\title{
És feminista la dansa oriental? Transferències culturals entre l'empoderament femení i l'imaginari orientalista
}

\author{
Maria Patricio Mulero \\ UNIVERSITÉ TOULOUSE JEAN JAURÈS \\ maria.patricio-muleroßuniv-tlse2.fr \\ ORCID: 0000-0001-5333-9727
}

\author{
Caroline Achouri* \\ UNIVERSITÉ TOLOSA JEAN JAURÈS. PROFESSORA DE DANSA ORIENTAL \\ caroline.achourifafree.fr
}

Rebut: 04/06/2019

Acceptat: 04/09/2020

\begin{abstract}
RESUM
La dansa oriental és un dels símbols més importants de la identitat d'Egipte com a atracció turística, i la seua pràctica s'ha estés per tot el món des de les últimes dècades del segle Xx. No obstant això, aquesta dansa ha tingut diferents recepcions depenent del període històric i dels públics. Amb un origen encara incert, la popularització de la dansa oriental va arribar amb el colonialisme, per representar-se després en les pel-lícules de l'era daurada de Hollywood, construïda com una fantasia oriental. Durant el segle xx i fins hui, mentre els mons de l'art egipcis neguen la inclusió de la dansa oriental en el concepte d'art, la disciplina segueix ensenyant-se per tot el món i ha evolucionat en noves disciplines, com l'ATS o la Tribal Fusion. Aquesta primera contradicció entre la recepció egípcia i l'estrangera és crucial, especialment per a les artistes de dansa oriental en el món àrab. Però una altra ambigüitat estableix una altra qüestió global sobre el gènere: mentre que els ballarins consideren la dansa oriental com una expressió feminista d'empoderament i alliberament, el públic d'Occident percep els espectacles com a objectificació de la dona. És la dansa oriental una disciplina que ha de ser experimentada per a exercir el feminisme? Quines són les condicions que permeten la recepció de la dansa oriental com a empoderadora per a les dones? És la recepció ambigua de la dansa una conseqüència de les diferents explicacions sobre els seus orígens i un imaginari particular d'Orient?
\end{abstract}

Paraules clau: dansa oriental, feminisme, orientalisme, Egipte, violència, empoderament.

ABSTRACT. Is Oriental Dance Feminist? Cultural transfers between women's empowerment and the Orientalist imaginary Belly-dancing is one of the things we associate with Egypt and it has become a major tourist attraction. The dance has spread round the world since the late $20^{\text {th }}$ Century. Nevertheless, the dance has been received differently depending on tastes at the time and audiences. Belly-dancing's origins remain murky but we know that it became popular during colonial times. It became much more widely known during Hollywood's 'Golden Age' when it was used as an Orientalist fantasy. From the 20th Century to the present, the Egyptian art world has refused to include belly-dancing as an art form. However, that has not stopped it spreading world-wide. Belly-dancing is now taught all over the globe and has even evolved into new disciplines such as ATS and Tribal Fusion. This first contradiction between home and foreign reception is a crucial one, especially for belly-dancers in the Arab world. Yet another ambiguity arises from the global issue of gender: while dancers consider belly-dancing as a Feminist expression of empowerment and liberation,

\footnotetext{
* Agraïments. A les meues mentores i mentors, Leila Haddad, Diana Tarkhan, Rachel Brice, Mahmoud Cala i lbrahim Akef.
} 
average audiences in the Western world see the shows as objectifying women. Is belly-dancing a discipline that must be experienced if one is to put Feminism into action? What conditions must be met so that belly-dancing can be seen as something that empowers women? Is the varied reception of belly-dancing a result of different explanations of its origins and a particular imaginary of The East?

Keywords: belly-dancing, Feminism, Orientalism, Egypt, violence, empowerment.

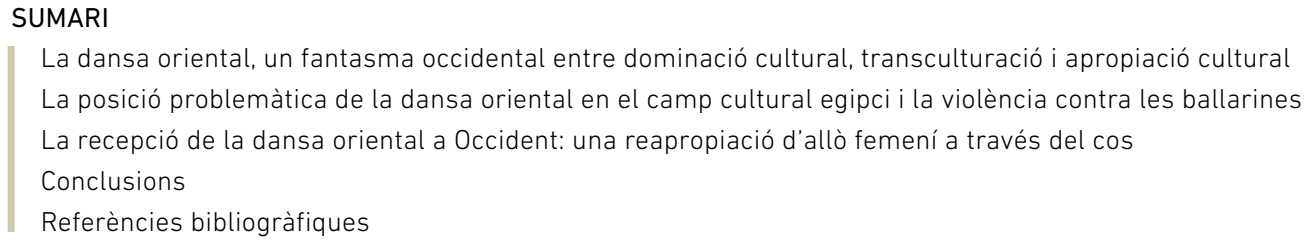

Autor per a correspondència / Corresponding author: Maria Patricio Mulero, 23 rue des salenques, apt 107. 31000 Toulouse (França). Citació suggerida / Suggested citation: Patricio Mulero, M. y Achouri C. (2020). És feminista la dansa oriental? Transferències culturals entre l'empoderament femení i l'imaginari orientalista. Debats. Revista de cultura, poder i societat, 134(2), 109-122. DOl: http://doi.org/10.28939/iam.debats.134-2.8

\section{LA DANSA ORIENTAL, UN FANTASMA OCCIDENTAL ENTRE DOMINACIÓ CULTURAL, TRANSCULTURACIÓ I APROPIACIÓ CULTURAL}

L'objecte d'aquest article és el solo ballat femení professional, denominat dansa oriental a Espanya i França, belly dance en els països anglosaxons i raqs el shaqî (dansa d'Orient) a Egipte. Les característiques que hui coneixem del solo femení van sorgir als anys 20 en els cabarets del Caire, equipaments d'oci a l'europea, i actualment el raqs el shaqî es troba present en festes, a la televisió i en les manifestacions públiques i privades d'Egipte (HenniChebra i Poché, 1996: 65). Si decidim observar en primer lloc la història de la construcció d'aquesta dansa és per demostrar el vincle inextricable que hi ha entre Orient i Occident al llarg de la seva evolució.

De fet, la dansa oriental es va construir, desenvolupar i professionalitzar —fins a convertir-se d'alguna manera en un símbol d'Egipte - a través de la mirada i la influència de la presència occidental a Egipte, des dels inicis del segle xIx: «Els orígens de la dansa oriental es troben en una complexa xarxa d'intercanvis interculturals des del segle xIx, dinàmiques globals de gènere i poder, i imatges reïficades creades per la mirada masculina colonial» (Burnam, 2012: 12). Paral-lelament, la influència de la dansa oriental s'ha sembrat a Occident, aportant una nova visió del cos femení i dels codis de feminitat, fins a influir en les coreògrafes pioneres de la dansa moderna del segle $x^{\mathbf{1}}$ - Loïe Fuller (2016), Ruth Saint Denis, Isadora Duncan (1999) — qui tenien

1 «De fait, Loïe Fuller (car la Danse Serpentine était en essence une réinterprétation de la "danse des voiles") tout comme Ruth St. Denis (dont le chef d'œuvre Radha. La danse des cinq sens mettait en scène une déesse indienne), recourent largement à l'imaginaire orientaliste» (Uffreduzzi, 2018). 
com a principal inquietud l'alliberament del cos femení. ${ }^{2}$

En el canvi de segle, lluny de la tradició del ballet, Loïe Fuller (1862 - 1928) i Isadora Duncan (1878 - 1927) van assentar les bases d'un nou art, produint estètiques singulars, teories sobre la dansa, les arts i el món. Amb elles s'inicia una era en què les dones dominaran la creació coreogràfica. Elles disposen del seu cos i de les seues representacions, qüestionen els estereotips vinculats a la dansa, controlen l'espai, gestionen la seua carrera personal i la seua companyia, pensen noves pedagogies. (Marquié, 2008) ${ }^{3}$

La dansa oriental es va construir a Egipte i a Occident de forma paral-lela segons els diferents processos d'intercanvis culturals, entre dominació cultural, transculturació i apropiació cultural: «Les idees globals sobre la dansa oriental i les pràctiques que s'hi associen es van construir transnacionalment a Egipte i als Estats Units en un entorn cultural d'explotació imperialista i les polítiques nacionalistes» (Burnam, 2012: 11).

El 1798, el general Bonaparte dirigeix la campanya d'Egipte, acompanyat no només de militars, sinó també d'escriptors, pintors i nombroses personalitats de la societat civil, majoritàriament homes. Ells seran els primers reporters de la societat egípcia de l'època. Com en tota relació entre una civilització dominant

2 «In Europe and North America at the end of the nineteenth and beginning of the twentieth centuries, a few dancers, of whom Ruth St. Denis and Maud Allan are among the best known, performed their interpretations of oriental dancing. Rather than using actual dances, they "brought to life" movements from iconic sources from the ancient Middle East. Throughout the twentieth century major film stars Theda Bara, Dolores Gray, Hedy Lamarr, and Rita Hayworth performed Broadway and Hollywood versions of this dance in biblical sagas, "Arabian Nights" films, and "Kismet" musicals from the earliest periods of the film industry. These productions helped to create the widespread icon of exotic dance as a representation of the Middle Eastern woman» (Shay i Sellers-Young, 2012).

3 Citacions traduïdes al valencià per l'equip de traducció de la revista a partir de les traduccions al castellà realitzades per les autores. i una altra de dominada, la mirada dels homes cap a la societat egípcia no va ser neutra ni estrictament informativa. Les primeres imatges de les ballarines orientals constituien representacions exagerades de la sexualitat que van justificar l'ocupació colonial, a través d'una percepció patriarcal colonialista (Burnam, 2012: 12-13) i d'una suplantació de les seues veus a través dels artistes orientalistes:

La relació entre Orient i Occident és una relació de poder i dominació [...]. Prenguem com a exemple la trobada de Flaubert amb una cortesana egípcia. [...] És ell qui parla per ella i qui la representa. No obstant això, és estranger, relativament ric, és un home, fets històrics que li permeten posseir-la no sols a nivell físic, sinó també parlar per ella i dir als seus lectors de quina manera ella és típicament oriental. (Said, 1978: 36) ${ }^{4}$

La mirada occidental era extremadament ignorant cap a una societat que descobrien com a colons, i sota la lògica de la dominació, no es tractava senzillament de conéixer una nova societat, sinó de sotmetre-la als postulats i als objectius de conquesta per part del dominant: «L'Oest era representat com a canviant, progressista, actiu, racional i auster; l'Est era rígid, estancat, passiu, irracional i sensual» (VanNieuwerk, 1995).

El descobriment de la dona oriental i de la dansa va formar part d'aquest procés. Entre les fantasies sobre els harems — als quals no havia pogut entrar cap viatger estranger, fora pintor, escriptor, soldat o polític 5 i la visió de les dones sense corset, en oposició total a un Occident purità on el cos de la dona era sovint «rigiditzat», es va generar una incomprensió

4 Edward Said es refereix a Koutchouk, cèlebre ballarina almée que va ser amant de l'escriptor francés Gustave Flaubert durant els seus viatges a Egipte.

5 «Les Occidentaux n'ont en tête que des harems élaborés à partir d'images que leurs artistes ont fabriquées - des tableaux et des films surtout (...). Mon harem se référait à une réalité historique. Le leur tire sa vitalité des images créées par des peintres comme Ingres, Delacroix, Matisse ou Picasso, qui prenaient plaisir à faire des femmes des odalisques (...). Images peintes ou images filmées, voilà le territoire du harem occidental (...)» (Mernissi, 2000: 20-21). 
enfront del sentit de les danses que podien veure en els carrers durant les festes tradicionals i socials, i el malentés es va generar ràpidament, reforçat per una convicció: l'erotisme era un dels aspectes principals de l'Orient exòtic» (Van Nieuwerk, 1995). Ràpidament, les danses van ser qualificades com a «voluptuoses, vergonyoses, estúpides, abjectes o salvatges» (Van Nieuwerk, 1995).

Cal precisar que, en arribar a Egipte, els occidentals van identificar dos tipus de ballarines. D'una banda, hi havia les a'oualem, que no actuaven en públic sinó en les cases de les classes acomodades i sobretot als harems, sense contacte amb els homes (HenniChebra i Poché, 1996: 68) ${ }^{6}$. D'altra banda, les ghawa$z i$ actuaven sense vel als carrers i davant dels cafés, per la qual cosa eren més accessibles als estrangers (Van Nieuwerk, 1995). Aquesta segona categoria de ballarines és l'única que els occidentals van poder observar de primera mà. Les ghawazi eren poc valorades per les classes altes locals, per la qual cosa rarament ballaven en cases particulars, fet que també va influir en la valoració que en feren els estrangers: «En el seu Description de l'Egypte (1821-1829), G. A. Villoteau va qualificar aquesta dansa com a indescriptible i va jutjar els moviments que la componien com a perfectament obscens» (Henni-Chebra i Poché, 1996: 67).

Aquest binomi de fascinació i repulsió per les dones que ballaven va trastornar completament la forma de representar la dansa. La mirada masculina occidental va transformar la dansa, d'una banda, cosificant la ballarina i sexualizant-ne tots els moviments, i d'altra banda, professionalitzant-la d'alguna manera, ja que els occidentals van començar a pagar les ballarines per veure-les ballar i posseir-les. En contrapartida, tot i tindre una reputació escandalosa, les

6 «Conformément aux coutumes locales, le maître de maison et ses invités écoutaient chanter les a' oualem depuis une pièce voisine du harem, ou depuis la cour de la maison. A l'arrivée des Français au Caire, ces dernières refusant de chanter devant des hommes et en particulier devant des soldats français, s'éloignèrent de la capitale» (Henni-Chebra i Poché, 1996: 68). ballarines van trobar la forma de guanyar-se la vida i emancipar-se: van començar a modificar la dansa per adaptar-la a les expectatives de l'home occidental. Aquest moviment no va parar d'intensificar-se durant la dominació anglesa d'Egipte en el segle XIx. La societat egípcia, per la seua banda, deplorava aquest entusiasme i condemnava frontalment la dansa oriental com a contrària a la seua cultura, la seua religió i els seus costums. ${ }^{7}$

Els orientalistes van tornar a Europa carregats de dibuixos, quadres, assajos i llibres que exposaven una visió errònia d'Orient, oblidant la realitat d'una àrea conquistada i sotmesa. Les obres orientalistes van fomentar a Europa la fantasia d'un Orient lasciu, passiu, entregat, amb una imatge de la feminitat $i$ de la dansa que va calar en l'imaginari col-lectiu occidental. Els primers dies de la dansa oriental van aparéixer en oposició a la societat de la qual va sorgir i sota la influència d'una mirada occidental totalment fascinada per la fantasia d'Orient.

L'harem dels occidentals, segons pareix, és una espècie de lloc orgiàstic on els homes aconseguixen un miracle impossible en Orient: disfrutar sense traves de la multitud de dones que han reduït a l'esclavitud! En el seu harem, les dones no intenten venjar-se per haver sigut agredides, sotmeses, rebaixades a l'humiliant estatut de captives. [...] D'aquesta manera he actualitzat el segon tret distintiu de l'harem occidental: l'intercanvi intel-lectual, obstacle per al plaer, és inútil. [...] Hi havia, entre altres fantasies, la dona muda, passiva tant intel-lectualment com físicament. (Mernissi, 2000: 36-37)

A finals del segle xIx, els occidentals van poder finalment gaudir d'aquesta fantasia oriental en els seus països. Les exposicions colonials a Europa i Estats Units $(1866$ - 1948) van portar les primeres ballarines orientals als pavellons d'Egipte, però també

7 «The excessive European interest in female dancers, and the fact that Europeans monopolized the dancers' services, intensified the dissatisfaction of the ulamâ and caused a more general Egyptian protest» (Van Nieuwerk, 1995). 
del Magrib. La transformació de la dansa, adaptada a les expectatives i a la mirada dels occidentals va seguir el seu curs, fet que va tergiversar encara més la realitat. Sol Bloom, productor americà d'espectacles, explica la trobada que va tenir amb la «cultura algeriana» durant l'exposició colonial a París el 1889, i el seu desig de promoure aquesta «falsa realitat»:

De totes les exhibicions de la fira, les de les colònies franceses m'han paregut les més fascinants. Dubte molt que res paregut s'haja vist mai a Algèria, però no em preocupaven les foteses. Els algerians eren genuïns sens dubte, i el que era realment important era que representaven un entreteniment variat que anava incrementant la meua excitació a mesura que $\mathrm{m}^{\prime}$ hi anava familiaritzant. Sabia que en l'hemisferi occidental mai s'havia vist res igual que eixes ballarines, acròbates, menjadors de vidre i menjadors d'escorpins, i estava segur que podria fer fortuna amb ells als Estats Units. (Burnam, 2012)

Aquesta és la visió de la dansa que ha inspirat Occident i Orient i que s'ha propagat per Europa i els Estats Units fins arribar a influir en la dansa occidental. Un entusiasme frenètic va envair els cabarets occidentals i tot tipus de locals d'espectacles, fins a coincidir amb l'alliberament del moviment i del cos de la dona, amb les premisses de la modern dance de principis del segle $\mathrm{xx}$, amb les americanes Loïe Fuller, Ruth Saint Denis i Isadora Duncan. En aquesta fase s'inicia un nou procés de reapropiació. Per millorar la reputació d'aquesta inspiració, aquestes ballarines van buscar les arrels divines d'un temps ancestral en què aquestes danses eren sagrades, una visió completament hipotètica no contrastada amb cap estudi de referència. Presentaven un feminisme «natural» i universal a través de nocions essencials de les dones i el cos, la raça i la nacionalitat, amb la idea d'un Orient misteriós i espiritual que legitimaria el cos com a vehicle d'expressió (Burnam, 2012).

Per la seua banda, les ballarines de les exposicions colonials s'acomodaven perfectament a les noves expressions $\mathrm{i}$ intentaven intensificar aquesta fan- tasia per quedar-se a Occident i desenvolupar una carrera en locals on podien ballar amb seguretat. En eixa època s'usaven els termes «Hoochee-Coochee» o «The Shimmy and Shake», i algunes ballarines van aconseguir un gran prestigi, com la síria Fahreda Batre Spyropoulos, o Fatima Djemille (d'origen desconegut), anomenades conjuntament Little Egypt. La dansa es va transformar, amb moviments pelvians cada cop més pronunciats (Edison, 1896; The original Little Egypt, 2013), vestimentes que començaven a mostrar el ventre, joies, perfums i llargues cabelleres soltes. Tots aquests detalls es van introduir per adaptar-se a la fantasia occidental. Les ballarines que tornaven a Egipte transmetien la nova visió a les ballarines egípcies, les quals, en els cabarets del Caire, remodelaven poc a poc la dansa per adaptar-se a la nova tendència.

L'exotisme d'esta dansa tan visual no va passar desapercebut a la indústria del cine de Hollywood, que es trobava en plena expansió: moltes pel-lícules històriques, bíbliques i mitològiques van optar per representar aquest tipus de dona oriental. Actrius com Hedy Lamarr (Samson and Delilah, de Cecil B. De Mille, 1949) o Rita Hayworth (Salomé, de William Dieterle, 1953), van encarnar belleses orientals, amb evident influència de la dansa oriental amb l'ús de vels, ventre descobert i peus descalços. ${ }^{\mathbf{8}}$ Paral-lelament, al Caire, la producció cinematogràfica també es troba en ple auge:

1932 [...], punt de partida d'una nova època en la història del cine egipci, que va començar a explotar la fascinació popular per la cançó i el gust de la petita burgesia per la «dansa turca» (anomenada dansa del ventre a Occident atribuïda al folklore àrab per error) executada al ritme d'una musiqueta oriental heteròclita (turcoàrab-judeo-mediterrània!). Aquesta xicoteta

8 «Les Américains, eux, me décrivaient leurs danseuses hollywoodiennes en voiles vaporeux aux couleurs de bonbons acidulés (...). Hollywood avait une expression pour ces mélos orientalo-suggestifs: «T and S». T est la première lettre de tits «nichons», et $\mathrm{S}$ est la première lettre de sand «sable» (Mernissi, 2000: 20-21). 
burgesia va començar a freqüentar cada vegada més aquest nou gènere de cine egipci, que atreia també les multituds populars. Les sales de cine es van multiplicar ràpidament (fins arribar a la xifra de 50) així com el nombre de pel-lícules realitzades i difoses durant aquest període. (Farid, 1973: 25)

Les ballarines egípcies de cabaret del Caire, com Samia Gamal o Tahia Carioca, apareixen en les pantalles de cine i provoquen la mateixa fascinació que als Estats Units. Les representacions de Hollywood i el Caire col-lideixen. La imatge de la ballarina oriental amb vestit de dos peces (faldilla i sostenidors) i els cinturons de lluentons es convertixen en la visió més estesa en el cine nord-americà i egipci, i influeix en els cabarets orientals i occidentals. El vestuari hui generalitzat no és més que una visió hollywoodiana de la dansa oriental, a la qual les ballarines egípcies es van adherir. Com que la presència occidental sempre va ser important a Egipte —especialment en el període d'entreguerres - , es van homogeneïtzar les diferents representacions de la dansa oriental.

El vestuari es «va orientalitzar» amb purpurina, granadura i perles en un estil que devia la inspiració sobretot a Hollywood. El vel, preeminentment oriental, es va introduir per incrementar la imatge de vampiressa misteriosa de les ballarines. Als anys 20 , el vestit de cabaret occidental s'havia convertit en una presumpta disfressa oriental, és a dir, un top de biquini amb lluentons, una falda de gasa baixa amb obertures laterals, i el ventre descobert. La versió orientalitzada, introduïda a Egipte per ballarines i les primeres pel-lícules americanes, va influir molt la indústria cinematogràfica egípcia en la dècada dels anys trenta i es va anar introduint gradualment en la vida nocturna egípcia. (Van Nieuwerk, 1995)

És aquesta la imatge que representa hui la ballarina egípcia, i per extensió, la dansa oriental, en l'inconscient col-lectiu. No és estrany trobar turistes, viatgers $i$ apassionats d'Egipte que creuen sincerament que la dansa oriental sempre ha sigut així, amb eixe vestuari i eixa forma de ballar. I en realitat sorgeix d'un contacte recent entre dos cultures, una relació asimètrica de dominació entre Orient i Occident, amb un rerefons de colonialisme patriarcal, per a reflectir-se després en les societats occidentals i remodelar la visió de la feminitat.

Ens pareixia impossible ometre aquesta realitat històrica, necessària per comprendre millor els reptes que oferix la dansa oriental. A Orient crea un rebuig cap a la ballarina oriental i el que representa, però a pesar de tot, a contracorrent de tot un sistema (religiós, social i de l'estatut de la dona), forma part incontestable de la societat actual, i ens parla d'aquesta societat. I a Occident genera fascinació per aquesta dansa exclusivament de gènere, i que per això aporta un discurs sobre la feminitat, l'empoderament $i$, per tant, el feminisme.

\section{LA POSICIÓ PROBLEMÀTICA DE LA DANSA ORIENTAL EN EL CAMP CULTURAL EGIPCI I LA VIOLÈNCIA CONTRA LES BALLARINES}

Si la complexitat dels orígens de la dansa oriental deriva en interpretacions completament diferents de la dansa, la posició de la dansa oriental en el camp cultural egipci no és menys controvertida. Partint en primer lloc de la representació de la dona com a intèrpret artística —com hem destacat abans, en el solo de dansa oriental-, la recepció ve condicionada per la complexa relació que té el públic egipci amb aquesta expressió artística. Relacionada amb la dominació occidental, sota l'opressió de la qual es va desenvolupar als cabarets de principis del segle xx, la societat egípcia no considera la dansa oriental com a patrimoni propi. En aquest context, l'adscripció de la dansa oriental com a part del camp cultural no posseeix legitimitat ni consagració artística. Els egipcis relacionen les interpretacions de les ballarines orientals amb els cabarets del Caire, els espectacles obligats a les bodes i el cine dels anys cinquanta. ${ }^{9}$

\footnotetext{
9 Menció a part mereix la representació de la ballarina oriental al cine egipci dels anys 50 , una imatge que es va transmetre a tot el món àrab i que es continua associant a Egipte.
} 
Si a aquesta situació de rebuig hi afegim que les ballarines no disposen de canals per manifestar el propi discurs respecte al valor cultural de la dansa, entendrem la posició marginal que ocupa. No obstant això, hi ha acusacions d'apropiació cultural a les ballarines occidentals per practicar eixe patrimoni injuriat en la seua pàtria original. L'escena cairota contemporània compta amb un elevat nombre de ballarines procedents d'Occident. Les històries sobre les seues trajectòries professionals són diverses, però generalment coincideixen a evocar una fascinació primerenca per la imatge relacionada amb una bellesa intemporal i femenina de les ballarines: «Estava fascinada i volia convertir-me en eixa ballarina que el públic esperava i desitjava. Com que tenia una mala imatge de mi mateixa, somiava amb la transformació de l'aneguet lleig en princesa»10

La ballarina Diana Tarkhan va descobrir la dansa als cafés de Belleville (París) el 1975, i va viatjar al Caire per primera vegada quatre anys més tard. Al poc temps es va instal-lar com a ballarina i professora de dansa. En aquella època encara eren poques les occidentals que actuaven, «de manera que les egípcies no sabien molt bé què pensar d'aquestes estrangeres: si eren una amenaça potencial o un objecte risible». La seua experiència a Egipte desprén la complexitat que rodeja la situació de la dansa oriental:

No es pot dir que ballar a Egipte siga fàcil, té un preu determinat i cal ser capaç de descodificar ràpidament els usos i costums, a risc de trobar-se en situacions que seria preferible evitar. [...] La forma com les egípcies perceben les ballarines és ambivalent, són adulades i odiades. Són dones de mala vida que han caigut en el pecat i que desvien l'home honest de la seua dona i la seua família. Aquesta és la posició oficial. Moltes persones ho pensen i són més nombroses hui que quan vaig arribar a Egipte. (ibíd.)

10 Entrevista realitzada per aquest article per les autores el maig del 2019 a la ballarina francesa Diana Tarkhan, que fou ballarina al Caire durant dècades.
Sonya, ballarina professional que actualment treballa al Caire en el vaixell-cabaret Nile-Maxim, explica que va tancar l'escola que tenia a França per viure «el seu somni al Caire». El públic del vaixell és bàsicament familiar i turístic, mentre que el jovent cairota assisteix als espectacles que fa en discoteques. Les seues alumnes del Caire són majoritàriament estrangeres, i les egípcies que fan classes amb ella ho fan «per plaer personal».

La doble percepció de la dansa en la societat, admirada per l'aura imaginària que envolta una tècnica complexa del cos femení i detestada per imperatius morals i religiosos, genera contradiccions com la de les dones de l'alta burgesia que explicaren a Tarkhan que havien aprés a ballar mirant cine egipci, desenvolupant una tècnica professional, i li confessaren que hagueren volgut ser ballarines «si hagueren pogut». Però si la respectabilitat de les egípcies perilla si admiren la dansa, les professionals estrangeres també temen que el seu ofici no estiga completament acceptat, ni tan sols entre les classes educades:

Vaig aprendre ràpidament a no parlar del meu ofici davant d'egipcis de qui no coneixia les opinions. De fet, aquest ofici m'obligava a seleccionar els meus coneguts entre els egipcis que mostraven una actitud liberal. I dic «mostraven», perquè és possible que en el fons siga un judici de valor d'acord amb el pensament majoritari. Per a detectar açò, cal temps i coneixement de la cultura. Quan ho perceps, tens la sensació d'haver sigut enganyada. (ibíd.)

La mateixa paradoxa li ocorre a Sonya, qui explica que les seues amigues expatriades saben a què es dedica, però en canvi, en el barri on viu creuen que treballa en l'exportació de bosses de mà per evitar que la consideren «una dona fàcil».

Respecte a la recepció entre els estrangers que visiten el Caire, Tarkhan no detecta més comprensió: «Per a ells es resumeix en una forma de striptease, una exhibició vulgar, perquè no poden en absolut descodificar aquesta dansa, ni el sentit de l'hu- 
mor que sovint l'acompanya». Per a Tarkhan, les ballarines orientals són percebudes igual que en l'imaginari occidental del segle XIX, «on el burgés i l'aristòcrata van a gastar-se els diners i a envilir-se per escapar del pes de les funcions oficials que se'ls atorguen». Al llarg del segle xx s'ha mantingut l'associació de la dansa oriental relacionada amb el luxe i l'alcohol dels cabarets, llocs on es toleren aquests hàbits pel contacte històric amb la població occidental. Hui la burgesia egípcia, incloent-hi les dones, assisteix als cabarets, que continuen sent un refugi per a aquests hàbits.

La societat egípcia segueix sense considerar el que denominem dansa oriental com a patrimoni cultural o una dansa folklòrica, ${ }^{11}$ quan paradoxalment és un dels productes turístics més cotitzats des de fa aproximadament un segle. Malgrat la complexitat tècnica dels moviments i el fet que la dansa oriental egípcia és la base de totes les derivacions artístiques de les altres disciplines Tribal i Fusion Bellydance, considerades danses de ple dret a Occident, la dansa oriental depén administrativament del Ministeri de Turisme egipci, i no del de Cultura, cosa que demostra la seua vinculació amb el públic estranger. ${ }^{12}$

La situació actual de les ballarines orientals en els països àrabs segueix les pautes d'altres repressions relatives a l'emancipació femenina vinculades amb els règims religiosos. A l'Orient Mitjà, la dansa oriental com a pràctica professional està molt desprestigiada, tant pel puritanisme com pel costum que dicta que les dones no han d'aparéixer descobertes davant d'homes amb qui no tenen parentiu. Les ballarines que apareixen en públic són percebudes

11 Les danses folklòriques van adquirir la seua legitimitat cultural amb la direcció de Mahmud Reda, coreògraf encarregat d'institucionalitzar-les.

12 «En el camp artístic egipci, la dansa oriental pateix una doble marginalització: per una banda, la pressió religiosa i la jerarquia eurocèntrica pressionen els poders governamentals per promoure únicament les danses folklòriques tradicionals i la dansa clàssica, com el ballet per altra banda, la reivindicació de la dansa com a femenina s'ha convertit en un obstacle per reconèixer-la com a art escénica» (Tena Medialdea, 2015). per la societat egípcia com a desobedients d'aquests costums i en l'imaginari social es vincula les professionals de la dansa amb la prostitució. En els basars del Caire, els venedors denuncien amenaces perquè no es venguen determinats vídeos de ballarines. Tot i que les creences fonamentalistes no són universalment acceptades, aquest tipus de dansa és molt controvertit en les societats musulmanes, a diferència de les danses regionals folklòriques (Shay i Sellers-Young, 2012).

Al marge de la percepció en relació al públic masculí, les professores de dansa oriental a Egipte treballen de forma pràcticament clandestina, i segons Tarkhan, els egipcis ignoren que les egípcies fan classes. «A més, si eres estrangera exercint la professió a Egipte, es crea un ressentiment, com si estigueres cometent un robatori cultural». No obstant això, la discriminació cap a la ballarina oriental, independentment del seu origen, degenera en violència, especialment aplicada a les professionals egípcies, ja que agredir una occidental està severament castigat. «Els insults, les violacions, el xantatge econòmic i el menyspreu són freqüents», explica Tarkhan.

Una de les paradoxes més importants en el camp cultural egipci és que és precisament el consum dels occidentals -els circuits turístics inclouen sempre un espectacle de dansa- el que ha aconseguit preservar la dansa oriental fins hui a pesar de la voluntat dels sectors religiosos que hi han actuat en contra, especialment des de la revolució. El públic occidental es troba igualment dividit entre dos recepcions de la dansa: d'una banda, els que la consumeixen com a producte exòtic, i en segon lloc, un grup format per amateurs o professionals de la dansa, que s'hi aproximen com un retorn a les arrels. L'excel-lència tècnica i interpretativa de la dansa oriental egípcia és reconeguda per les ballarines occidentals, que acostumen a viatjar sovint a Egipte per seguir-se formant. Alguns estudis apunten a un cert discurs orientalista per part de les ballarines occidentals (Hooi, 2015) que perpetuaria una mirada colonialista, reforçada per un imaginari romàntic criticat pels estudis postcolonials. Altres, no obstant això, 
afirmen que la dansa oriental moderna és un «estil autònom fruit de la cultura urbana de fin-de-siècle i caracteritzat per ser transnacional i híbrid» (Tena Medialdea, 2015). Finalment, la tesi de Caitlin McDonald exposa com la dansa oriental introduïda en els processos de globalització dialoga constantment amb les cultures que l'acullen, la desenvolupen i acaben influint-hi, mantenint en tots els casos una centralitat com a eina feminista de construcció de la feminitat, una consideració contemporània i bàsicament occidental (McDonald, 2010).

\section{LA RECEPCIÓ DE LA DANSA ORIENTAL A OCCIDENT: UNA REAPROPIACIÓ D’ALLÒ FEMENÍ A TRAVÉS DEL COS}

A partir de la dècada dels 90, la transmissió de la dansa oriental s'ha desenvolupat a Occident de forma exponencial fins hui. Aquesta fascinació es tradueix en una àmplia oferta de classes, tot i que la situació inestable en els països d'Orient Mitjà i una actualitat preocupant en aquesta regió hagueren pogut crear una desafecció (Apprill, Djakouane i Nicolas-Daniel, 2013). La predominança de la imatge orientalista basada en una intemporalitat de la ballarina pareix desconnectada d'una realitat geogràfica i política. A la vista d'aquest fet, resulta interessant entendre les motivacions que mouen les alumnes dels cursos de dansa oriental, excloent la cultura d'un país i la seua realitat actual.

L'experiència de Caroline Achouri com a professora de dansa oriental des de fa 20 anys a França m'ha permés comprendre les raons més o menys conscients que porten les occidentals a fer classes d'aquesta disciplina. Una primera conclusió s'imposa: les alumnes de dansa oriental tenen majoritàriament molt pocs vincles amb la cultura oriental. Una segona observació és la importància de la ballarina i de la dona oriental com a motor inicial, inclús si les alumnes no tenen cap referència precisa de cap ballarina oriental real, històrica o contemporània. Es tracta «essencialment de familiaritzar-se amb els ritmes i els moviments i d'adherir-se a un imaginari exòtic de la dansa oriental» (Boldrin, 2015).
Al contrari, la qüestió de la feminitat s'evoca sovint en termes de seducció, gràcia, voluptuositat, bellesa, llibertat del cos. Amb aquestes associacions, semblaria que ens trobem davant d'una cerca individual i personal de reapropiació del cos femení, amb l'afegit de succeir en un lloc - l'acadèmia de ball- de caràcter generalment no mixt. ${ }^{13}$ Poder ballar lluny de la mirada masculina i dels dictats socials sobre la identitat femenina sembla permetre una experiència de llibertat i de recerca de la identitat de la dona:

La pràctica de la dansa oriental dins de les classes és un moment de joc, de sensualitat, de posada en escena d'una mateixa, sota la mirada masculina. [...] Exterioritzar el plaer del moviment i del deixar-se anar emocionalment, guiades per la música, afavoreix l'experimentació de noves relacions amb una mateixa. Per a les dones occidentals en particular, l'expressió de les emocions és sovint considerada com una actitud vergonyosa, que deroga la imatge social i professional que cadascú ha d'assumir. [...] En un espai tancat com és la classe de dansa, moltes dones aprenen una corporeïtat emocional. (Boldrin, 2015)

Resulta paradoxal dirigir-se a una altra cultura i utilitzar una de les expressions icòniques d'eixa cultura, no per a conéixer-la, sinó per a conéixer-se més a una mateixa, en el propi context cultural. No es tracta en la majoria dels casos d'una mirada cap a l'exterior, sinó del retorn a una mateixa i a la identitat pròpia, sota l'aparença d'un desenvolupament personal i d'un empoderament femení. La primera persona a qui volen conéixer i seduir les alumnes de dansa oriental és a elles mateixes com a dones.

Les evolucions de la disciplina de la dansa oriental han seguit el camí de la introspecció femenina, sense aproximar-se amb curiositat a la cultura oriental i, no obstant això, amb distància respecte de la imatge de

13 Aquesta no sol ser una decisió de la professora, sinó que l'experiència constata que generalment les classes de dansa oriental són molt poc freqüentades pel públic masculí, la participació del qual continua sent anecdòtica. 
la ballarina de cabaret cairota. L'exemple de la Tribal Bellydance, i particularment la seua primera branca, l'American Tribal Style ${ }^{\circledR}$, és revelador. Aquest estil de dansa va nàixer a San Francisco, la meca del new age, a principis dels huitanta. Va ser creat per nordamericans que tenien una idea llunyana de la cultura d'Orient Mitjà, i van adoptar diferents estètiques de danses anomenades orientals, en un sentit ampli, que comprenien des del Magrib i Egipte fins a l'Índia. Respecte a la filosofia que mou la dansa -no entrarem a detallar-ne la tècnica-, cal destacar que, en lloc de voler seduir amb una mirada sovint masculina, busca la solidaritat entre dones i la sororitat d'una «tribu» exclusivament femenina que balla entre i per a elles, per trobar una força col-lectiva exclusivament femenina. L'anècdota del nom de la tribu creada per Carolena Nericcio, fundadora de l'ATS $\circledR^{\text {és reveladora: }}$

Quan vam haver de buscar un nom per a la companyia de ball, un amic va suggerir la rima FatChanceBellyDance, a partir de la pregunta absurda que es fa a les ballarines, per part d'un públic que pensa que la bella i femenina dansa oriental és simplement un entreteniment exòtic per al seu plaer personal. En altres paraules, la resposta és «Ja pots esperar sentat si esperes que et faça un xou privat». ${ }^{\mathbf{1 4}}$ (Nericcio, 2019)

La desviació de la mirada és en aquest cas evident, perquè es dirigeix a una mateixa, i només té importància respecte a una mateixa i al grup amb què es balla. La mirada exterior del públic i les expectatives que tinga (o les fantasies) són enterament secundàries. Es tracta d'un empoderament col-lectiu en femení, on totes les descodificacions de la dansa oriental es posen en dubte: el vestuari és molt més cobert, la noció de solista es dilueix en una dansa de grup, en l'interior de la qual la imatge de la feminitat és múltiple, inclús la música, que no sol pertànyer al repertori oriental. El que interessa al corrent coreogràfic de la Tribal BellyDance és més la recerca de les feminitats i com s'expressen, que no l'adhesió a una cultura i a la seua història. Com explica Tina Frühauf

14 «Fat chance you can have a private show», de l'anglés original. respecte al Gothic Bellydance: «Aquesta dissociació d'Orient — podem anomenar-la una descolonització cultural- no és tant una decisió conscient com una evolució genuïna» (Frühauf, 2009).

Es tracta realment d'una «descolonització» o més aviat d'una forma d'apropiació cultural? Aquesta fugida de la cultura i la història d'origen en la pràctica occidental i en la recepció femenina suggereix algunes preguntes. La falta d'informacions veraces sobre els orígens de la dansa oriental, la distorsió per part de l'orientalisme, així com la falta de reconeixement en el seu país d'origen, obren la porta a diferents interpretacions i reescriptures de la realitat d'esta dansa. Així doncs, actualment no resulta estrany que, per deixar de banda la mala reputació de la dansa oriental, s'invente una nova història que li conferisca una respectabilitat mil-lenària i quasi divina, a la recerca de la «feminitat sagrada». No obstant això, aquesta visió no ha sigut demostrada ni recolzada històricament. No és la posició de les ballarines egípcies, que acusen les ballarines occidentals — sobretot les americanesd' «evocar la dansa oriental com una forma de comunió misteriosa i arcaica» (Boukobza, 2009). La motivació seria «legitimar la disciplina als ulls d'un públic ampli, inscrivint-la en una història mil-lenària que donaria testimoni de la pertinença als gèneres de rituals i erudits» (Garrec, 2013).

Els coreògrafs intenten valorar la dansa oriental atribuint-li un origen ancestral: seria l'hereua d'un ritu de fecunditat practicat als temples antics per ballarines-sacerdotesses en honor a la Deessa Mare. Però no hi ha cap empremta escrita o iconogràfica que testifique amb certesa una tradició mil-lenària de naturalesa sagrada. Com subratlla l'etnomusicòleg Christian Poché, «és cert que basant-se en el que és sagrat, la raqs sharquî seria automàticament legitimada i sostreta de l'oprobi que la rodeja». (Garrec, 2013)

Aquesta reinterpretació i reapropiació històrica transgredeix en reemplaçar en el seu discurs una realitat, no sols històrica, sinó també la realitat actual de les ballarines orientals a Egipte. El procés a través del qual la dansa oriental pot generar un 
empoderament femení i una consciència feminista és perfectament comprensible i acceptable, però no és fidel a la realitat en un context global en què precisament els dos hemisferis que practiquen la dansa oriental no es comuniquen. Com descriu l'exballarina professional Diana Tarkhan:

Si Occident sent la necessitat d'apropiar-se d'esta dansa per convertir-la en un símbol de reivindicació feminista, per què no? Però com justificar el fet de centrar-se a transformar el que les feministes perceben com un símbol de la dona objecte? Caldria, en aquest cas, modificar i redirigir aquest símbol cap al bon camí? Crec que és més complex, i que la lectura aplicada a la dansa oriental pel feminisme és massa reduccionista. Al cap i a la fi, pareix que les feministes volen justificar l'atracció que senten per eixa representació de la dona vestint-la amb noves gales, per fer acceptables els seus desitjos inconscients. ${ }^{15}$

Resulta paradoxal que a Occident es detecte un gran entusiasme per la dansa oriental acompanyat d'una falta de coneixement d'Orient que no sempre evoluciona cap a un interés o curiositat cap a la cultura oriental. L'experiència ens mostra que l'atractiu d'aquesta dansa pareix referir-se molt més a la cerca del que és femení, entés en aquest cas com a universal, més enllà de l'espai i el temps. D'aquesta manera, en l'imaginari occidental, paradoxalment, aquesta imatge femenina correspondria a una ballarina oriental.

Precisament, l'espectre de l'orientalisme és el que ha generat una autonomia de la ballarina cap a una evolució introspectiva en la pràctica amateur en l'Occident contemporani. Si, d'una banda, la performance en cabarets sembla atorgar una importància capital a la capacitat de la ballarina de seduir el públic, les declaracions de les ballarines permeten intuir que, més enllà del marc determinant econòmic, l'objectiu final de l'espectacle de dansa oriental no és la

15 Entrevista realitzada per les autores per al present article. reacció masculina, sinó la sensació de la pròpia ballarina. «La visió orientalista de la dansa desencadena un imaginari que juga a favor d'aquests objectius, relacionant per exemple els vestits com a expressió de poder sexual i, per tant, emanació d'una visió positiva del propi cos femení, relacionada amb el poder i la confiança, de forma molt més intensa que en altres estils de dansa» (Dox, 2006). A més, en el cas de determinades estètiques de les evolucions de la dansa oriental, com el Gothic Bellydance, l'estètica gòtica escollida i l'actitud distant de les ballarines que no busquen la interacció amb el públic, representen formes d'autonomia del subjecte dansaire respecte a la mirada masculina associada amb el públic de la dansa oriental de cabaret (Frühauf, 2009).

Hi ha nombrosos estudis sobre com la pràctica de la dansa en general aporta en els subjectes una eina fonamental de construcció de la pròpia identitat. Partint d'un feminisme materialista de construcció del gènere (Marquié, 2008, 2016), les noves metodologies en què l'investigador se situa com a practicant permeten comprendre millor l'impacte que aquesta pràctica té sobre les dones, per exemple en casos d'una relació problemàtica amb el cos o quan hi ha consideracions respecte a la mirada masculina en contextos patriarcals (Thorin, 2017). L'associació generalitzada de la dansa oriental amb el que socialment és reconegut com a femení representa el seu major atribut entre les occidentals que la practiquen (Reis i Zanella, 2010). Especialment, pel fet que la pràctica de la dansa des de qualsevol morfologia femenina «ofereix una escapatòria de la tirania dels estàndards de les imatges del cos en la moda i els mitjans de comunicació occidentals» (Dox, 2006).

Aquesta autonomia de les ballarines amateurs té lloc per una mala interpretació de la dansa per part la majoria del públic masculí. Si hem de jutjar pels testimonis de les ballarines professionals i amateurs, el públic masculí occidental encara no sembla haver comprés hui el poder emancipador de la dansa oriental ni posseir els codis per a comprendre el llenguatge de la dansa més enllà d'un exercici de seducció. No obstant això, com hem mencionat anteriorment, 
la motivació principal de les occidentals per a practicar-la sorgeix d'una voluntat de relacionar-se amb el seu propi cos, sense pensar necessàriament a actuar en públic. Però la perspectiva occidental sí que prevaleix a priori en els prejuís sobre la dansa, almenys en un estadi inicial. De la mateixa manera que una part de les ballarines amateurs accedeixen per primera vegada a la dansa oriental seguint una fantasia orientalista, la interpretació masculina de la dansa com a públic remet a una imatge patriarcal integrada en el colonialisme amb què es descodifica el món oriental, i particularment la dona oriental: una espècie de «consum eròtic» que a més d'accessible és barat (Deagon, 2018: 71). Andrea Deagon, acadèmica i ballarina oriental, parla de la seua pròpia experiència en explicar que les ballarines es perceben com a «criatures d'una sexualitat desempoderada i alhora entusiasta», en clara oposició amb la comunitat d'amateurs i professionals:

El discurs autodefinit de la comunitat de dansa del ventre als Estats Units busca mantindre's allunyat dels mercats d'esclaus i de les xiques de l'harem, centrant-se en canvi en la comunitat de dones, la història de les dones, la solidaritat femenina, el gaudi personal, l'experiència sensual, l'intercanvi cultural i l'art, sovint entrellaçat amb la teologia de la deessa. No obstant això, els espectres de venalitat, la sexualitat comercialitzable i el negoci del sexe es neguen a desaparéixer. Ja siga en fòrums d'internet o en classes i tallers, les ballarines nord-americanes estan en guàrdia contra les pràctiques de dansa sexualment contaminades, les critiquen amb vehemència i no les consideren com a dansa oriental. (Deagon, 2018)

No obstant això, les arrels de l'orientalisme patriarcal han calat profundament en l'imaginari occidental. Un exemple literari - per citar-ne només unés el de l'escriptor i crític francés Théophile Gautier, que exposa en Loin de Paris com interpretar la dansa de Zorah: un esclau il-lumina diferents parts del cos de la ballarina mentre balla, i el públic li ofereix monedes $i$ altres ofrenes col-locant-les en la part que més han admirat. Segons Deagon, Gautier mai con- sidera la possibilitat que foren els moviments, i no les parts del cos, el que Zorah decideix mostrar «com a artista i subjecte», sinó que l'escriptor ho relaciona directament amb propines a una apreciació parcial de la ballarina (Deagon, 2018: 75).

Aquest malentés interpretatiu pareix inherent entre les persones que practiquen la dansa, conscients que aquesta dansa contribueix a la construcció de la identitat femenina, i les que al llarg de la història l'han observat des de lluny, instituint-la en una fantasia autosuficient i ahistòrica. Malgrat tot, sembla que entre les ballarines s'imposa la més gran de les paradoxes, perquè tal com hem exposat anteriorment, no conceben la dansa de la mateixa manera depenent de l'hemisferi on la practiquen.

\section{CONCLUSIONS}

La complexitat de la interpretació de la dansa oriental prové del seu origen com a expressió artística híbrida vinculada a la història colonial d'Egipte i al moviment orientalista. L'evolució de la dansa està tan estretament vinculada a les relacions de dominació entre Egipte i les potències colonials (França i Regne Unit), que la recepció per part de les persones receptores ha sigut polèmica i condicionada. Les artistes egípcies són reconegudes en l'escena internacional però no formen part de l'àmbit cultural local, i no obstant això, la disciplina gaudeix d'un èxit global.

Precisament per la falta de reconeixement oficial de la dansa, que no és acceptada en la societat egípcia (a pesar d'exercir una certa fascinació), la transmissió a Occident ha permés obviar el context colonial en què va nàixer i potenciar una imatge orientalista en què, malgrat tot, l'empoderament femení, l'acceptació del propi cos i la sororitat entre dones serien característiques pròpies de la dansa des dels seus orígens. Les ballarines amateurs occidentals practiquen la dansa oriental des d'una òptica individual, busquen un benestar harmònic amb el seu cos i la construcció d'una identitat femenina. Probablement 
per desconeixement de la situació actual de les ballarines egípcies, o perquè l'objectiu personal transcendeix al col-lectiu, no pareixen manifestar interés per la contesa de les ballarines egípcies. En aquest context, tal vegada seria pertinent preguntar-nos si la dansa oriental a Occident no s'estaria transmetent com una forma d'apropiació cultural.

A Egipte, les ballarines orientals viuen una lluita quotidiana, sense teoritzar-la ni mostrar-la en els seus discursos, contra el sistema social, religiós i cultural que espera de la dona la discreció màxima i pudor, que la relega a la llar, i en cap cas l'anima a ballar en públic. Amb la seua presència, les ballarines que han trobat l'autonomia econòmica en la demanda turística viuen diàriament les dificultats de practicar una dansa que els permet una emancipació econòmica, però cap reconeixement social i les conseqüències de distintes formes de violència. Des del nostre punt de vista, tot i que aquestes conseqüències no es manifesten a través d'un discurs explícit en les seues declaracions, la lluita quotidiana i sense teoritzacions pot ser considerada com a feminista, cap a una autonomia de la dona artista i la representació legítima d'una forma de feminitat alliberada de les imposicions religioses i socials.

Ja que el punt de partida és la dansa oriental, resulta paradoxal que les dos interpretacions per part de les ballarines d'aproximar-se a la dansa en Orient $\mathrm{i}$ Occident no dialoguen entre elles per a participar d'una mateixa causa a favor de la dona i la seua emancipació. Actualment, mentre que les ballarines occidentals es dediquen a utilitzar la dansa per a desenvolupar pràctiques d'empoderament i sororitat, les ballarines egípcies, origen històric de la disciplina, s'enfronten diàriament $i$ de forma aillada als reptes contemporanis del patriarcat internacional.

REFERÈNCIES BIBLIOGRÀFIQUES

Apprill, C., Djakouane, A. i Nicolas-Daniel, M. (2013). L'enseignement des danses du monde et des danses traditionnelles. París: L'Harmattan.

Suriol, B. (26 d'agost de 2013). The Original 'Little Egypt'. [Vídeo] https://www.youtube.com/ watch?v=xLgk3Lsp6g8\&list=PL9YW2ILM5wI2Zj90PmwNOHSrU2_vWq-c1\&index=2

Boldrin, B. (2015). Le voile dans la danse orientale ou les codes du dévoilement de l'intime. Recherches en Danse, 4. DOI: $10.4000 /$ danse. 1110

Boukobza, J. (2009). Danser l'Orient: Touristes et pratiquantes transnationales de la danse orientale au Caire. Cahiers d'études africaines, 193-194, 203-226. DOI: 10.4000/etudesafricaines.18692

Burnam, A. R. (2012). Bellydance in America: Strategies for Seeking Personal Transformation. (Tesi doctoral, University of California, Los Ángeles, EE.UU).

Deagon, A. (2018). The Golden Mask : Tipping the Belly Dancer in America. Feminist Studies, 39(1), 71-97. Recuperat de https://www.jstor.org/stable/23719295

Dox, D. (2006). Dancing around Orientalism. TDR/ The Drama Review, 50(4), 52-71. DOI: 10.1162/dram.2006.50.4.52

Duncan, I. (1999). Ma vie. París: Gallimard.

Farid, S. (1973). Naissance et développement du cinéma égyptien (1922-1970). Ecran, 15, 21-33. Recuperat de http:// collections.cinematheque.qc.ca/wp-content/uploads/2013/06/DCQ_1984_13_p21-33w.pdf

Frühauf, T. (2009). Raqs Gothique: Decolonizing Belly Dance. TDR, 53(3), 117-138. Recuperat de https://www.jstor. org/stable/25599497

Fuller, L. (2016). Quinze ans de ma vie. París: Mercure de France.

Garrec, A. L. (2013). Danse indienne vs danse orientale. Divergence des danses extra-occidentales en France. Corps, $1(11), 315-322$. 
Henni-Chebra, D. i Poché, C. (1996). Les danses dans le monde arabe, ou l'héritage des almées. París: L'Harmattan.

Hooi, M. (2015). Oriental Fantasy: A Postcolonial Discourse Analysis of Western Belly Dancers' Imaginations of Egypt and Dance Festivals in Egypt. Linköpings universitet.

Marquié, H. (2008). Engagements chorégraphiques: Danse, féminisme et politique. Femmes, création, politique, Aug 2008. França: Cerisy-La-Salle.

Marquié, H. (2016). Non, la danse n'est pas un truc de filles! Essai sur le genre en danse. Tolosa: Éditions de l'Attribut.

McDonald, C. (2010). Bellydance and Glocalisation: Constructing Gender and on the Global Stage. (Tesi doctoral, University of Exeter, Regne Unit).

Mernissi, F. (2000). Le harem et l'Occident. París: Albin Michel.

Nericcio, C. (3 de juny de 2019). About American Tribal Style. Recuperat de https://fcbd.com/about/about-ats/

Reis, A. C. i Zanella, A. V. (2010). A constituição do sujeito na atividade estética da dança do ventre. Psicologia \& Sociedade, 22(1), 149-156. DOI: 10.1590/s0102-71822010000100018

Said, E. W. (1978). L'orientalisme. L'Orient créé par l'Occident. París: Éditions du Seuil.

Shay, A. i Sellers-Young, B. (2012). Belly Dance: Orientalism: Exoticism: Self-Exoticism. Dance Research Journal, 35(1), 13-37.

Watson, S. (20 de febrer de 2013). Little Egypt (Fatima Djemille) 1896 Edison. [Vídeo] https://www.youtube.com/ watch?v=LObvE8C5dGI\&list=PL9YW2ILM5wI2Zj90PmwN0HSrU2_vWq-c1\&index=4

Tena Medialdea, M. D. (2015). Danza oriental, género y políticas coloniales: Del cabaret moderno al mercado global de la cultura. Universitat de València. (Tesi doctoral, Universitat de València, València). DOI: 10.13140/ RG.2.2.33662.18241

Thorin, E. (2017). Dancing Interventions: A Feminist New Materialist Engagement in Three Dance Stories. (Tesi doctoral, Universiteit Utrecht, Països Baixos).

Uffreduzzi, E. (2018). Danse et orientalisme dans le cinéma muet italien. Danse \& cinéma, la recherche en mouvement, 1. Recuperat de https://imagessecondes.fr/index.php/2018/06/28/danse-et-orientalisme-dans-le-cinema-muet-italien/

Van Nieuwerk, K. (1995). A Trade like any Others : Female Singers and Dancers in Egypt. Texas: University of Texas Press.

\section{NOTA BIOGRÀFICA}

\section{Maria Patricio Mulero}

És doctora en Sociologia i Gestió de la Cultura per la Universitat de Barcelona i per la Université Paris 8 , amb la tesi $L a$ ciudad literaria. Representación urbana y creación literaria en Barcelona (1970 - 2015). Ha ensenyat llengua i civilització espanyoles en l'Institut d'Études Européennes de la Université Paris 8 i en la Université Toulouse Jean Jaurès.

\section{Caroline Achouri}

Té un màster en Literatura Moderna per la Université Jean Jaurès i és professora de dansa oriental i Tribal Belly dance (ATS® i Tribal Fusió Datura Style) a Tolosa des del 1997. Coreògrafa formada en el Centre de Dansa James Carlès i intèrpret, és directora artística de la companyia Al-Raqs i de les tribus Purple Haze i BellyWarda, a més de cofundadora del Festival Back to the Roots. Actualment les seues creacions coreogràfiques aborden els dos temes centrals de la seua trajectòria professional: la identitat femenina i les transferències culturals entre Orient i Occident. 